\title{
AMPA/Kainate Receptor-Mediated Downregulation of GABAergic Synaptic Transmission by Calcineurin after Seizures in the Developing Rat Brain
}

\author{
Russell M. Sanchez, ${ }^{1 \star}$ Weimin Dai, ${ }^{2 \star}$ Rachel E. Levada, ${ }^{2}$ Jocelyn J. Lippman, ${ }^{2}$ and Frances E. Jensen ${ }^{2,3}$ \\ ${ }^{1}$ Department of Pharmacology and Center for Biomedical Neuroscience, University of Texas Health Science Center, San Antonio, Texas 78229-3900, \\ ${ }^{2}$ Department of Neurology, Children's Hospital and Harvard Medical School, and 3Program in Neuroscience, Harvard Medical School, Boston, \\ Massachusetts 02115
}

\begin{abstract}
Hypoxia is the most common cause of perinatal seizures and can be refractory to conventional anticonvulsant drugs, suggesting an age-specific form of epileptogenesis. A model of hypoxia-induced seizures in immature rats reveals that seizures result in immediate activation of the phosphatase calcineurin $(\mathrm{CaN})$ in area $\mathrm{CA} 1$ of hippocampus. After seizures, $\mathrm{CA} 1$ pyramidal neurons exhibit a downregulation of $\mathrm{GABA}_{\mathrm{A}}$ receptor $\left(\mathrm{GABA}_{\mathrm{A}} \mathrm{R}\right)$-mediated inhibition that was reversed by CaN inhibitors. CaN activation appears to be dependent on seizure-induced activation of $\mathrm{Ca}^{2+}$-permeable AMPA receptors (AMPARs), because the upregulation of CaN activation and GABA $\mathrm{R}$ inhibition were attenuated by GYKI 52466 [1-(4-aminophenyl)-4-methyl-7,8-methylenedioxy-5H-2,3-benzodiazepine hydrochloride] or Joro spider toxin. $\mathrm{GABA}_{\mathrm{A}} \mathrm{R} \beta 2 / 3$ subunit protein was dephosphorylated at $1 \mathrm{~h}$ after seizures, suggesting this subunit as a possible substrate of $\mathrm{CaN}$ in this model. Finally, in vivo administration of the CaN inhibitor FK-506 significantly suppressed hypoxic seizures, and posttreatment with NBQX (2,3-dihydroxy-6-nitro-7-sulfonyl-benzo[f]quinoxaline) or FK-506 blocked the hypoxic seizure-induced increase in CaN expression. These data suggest that $\mathrm{Ca}^{2+}$-permeable AMPARs and CaN regulate inhibitory synaptic transmission in a novel plasticity pathway that may play a role in epileptogenesis in the immature brain.
\end{abstract}

Key words: glutamate receptors; $\mathrm{GABA}_{\mathrm{A}}$ receptors; calcium; epilepsy; hypoxia; FK-506

\section{Introduction}

Hypoxia is the most common cause of seizures in the neonatal period (Volpe, 2001). Neonatal seizures in the setting of hypoxic encephalopathy are associated with an increased risk of epilepsy later in life (Bergamasco et al., 1984; Bernes and Kaplan, 1994) and can be refractory to conventional anticonvulsant drugs that are effective in older children and adults (Painter et al., 1999). To investigate age-specific mechanisms of epileptogenesis in the neonatal brain, we used a rodent model that mimics the acute seizures and chronic proepileptogenic effects of neonatal hypoxia observed clinically. In this model, global hypoxia induces seizures in rat pups at postnatal day 10 (P10) to P12 but not in younger or older rat pups (Jensen et al., 1991, 1992). Furthermore, after hypoxia-induced neonatal seizures, rats exhibit long-term increases in seizure susceptibility (Jensen et al., 1991, 1992) as well as early and long-lasting increases in hippocampal and cortical

Received Dec. 29, 2003; revised Feb. 16, 2005; accepted Feb. 17, 2005.

This work was supported by National Institutes of Health-National Institute on Neurological Disorders and Stroke Grants R01 NS31718 (F.E.J.) and R01 NS047385 (R.M.S.), by the Epilepsy Foundation/American Epilepsy Society (R.M.S., W.D.), and by National Institute of Child Health and Human Development Mental Retardation Research Center Grant P30 HD18655.

*R.M.S. and W.D. contributed equally to this work.

Correspondence should be addressed to Dr. Frances E. Jensen, Associate Professor of Neurology, Division of Neuroscience, Enders 347, Children's Hospital, 300 Longwood Avenue, Boston, MA 02115. E-mail: frances.jensen@childrens.harvard.edu.

DOI:10.1523/JNEUROSCI.0204-05.2005

Copyright $\odot 2005$ Society for Neuroscience $\quad 0270-6474 / 05 / 253442-10 \$ 15.00 / 0$ network excitability (Jensen et al., 1998). In immature rats, hypoxia-induced seizures and chronic hyperexcitability can be blocked by treatment with antagonists to AMPA receptors (AMPARs) but not NMDA receptors (NMDARs) (Jensen et al., 1995; Koh and Jensen, 2001; Koh et al., 2004). Notably, the age window at approximately P10 is characterized by a relative preponderance of $\mathrm{Ca}^{2+}$-permeable AMPARs in hippocampus and neocortex resulting from a developmentally lower expression of the glutamate receptor 2 (GluR2) subunit compared with other AMPAR subunits (Durand and Zukin, 1993; Sanchez et al., 2001; Kumar et al., 2002). In addition, hypoxia-induced seizures at P10 induce a subacute and specific decrease in hippocampal GluR2 expression observed by $96 \mathrm{~h}$, which is associated with an increase in AMPAR-mediated potentiation of hippocampal epileptiform activity in vitro (Sanchez et al., 2001). Although these data suggest that seizure-induced regulation of $\mathrm{Ca}^{2+}$-permeable AMPAR expression critically contributes to the susceptibility of the immature brain to seizure activity, the specific mechanisms by which AMPAR-mediated $\mathrm{Ca}^{2+}$ influx induce hyperexcitability are as yet unknown.

Inhibitory GABA receptor (GABAR)-mediated synaptic transmission can be negatively modulated by the endogenous phosphatase calcineurin-A (CaN-A) (Huang and Dillon, 1998), and CaN-A can be activated by seizures in vivo (Kurz et al., 2001). Because CaN-A activation is $\mathrm{Ca}^{2+}$ dependent, we hypothesized that AMPAR-mediated activation of CaN-A during and after hy- 
poxic seizures may contribute to hippocampal hyperexcitability by acutely downregulating inhibitory synaptic transmission. Here, we report that hypoxia-induced seizures in the immature brain induce immediate decreases in GABAergic synaptic inhibition of hippocampal CA1 pyramidal neurons, and that this downregulation requires the postsynaptic activation of $\mathrm{Ca}^{2+}$ permeable AMPARs with secondary activation of the phosphatase CaN-A. Our results also demonstrate that hypoxia-induced $\mathrm{CaN}$ activation is associated with dephosphorylation of native $\mathrm{GABA}_{\mathrm{A}}$ Rs, suggesting a mechanism by which GABAergic inhibition may be downmodulated. Additional support for a role for $\mathrm{CaN}$ in hypoxia-induced excitability is provided by the observation that the CaN inhibitor FK-506 suppressed hypoxia-induced seizures in immature rat pups. Together, these results indicate that $\mathrm{Ca}^{2+}$-permeable AMPARs can mediate CaN-dependent downmodulation of hippocampal GABAergic inhibition to promote seizures in the immature brain, and that $\mathrm{CaN}$ inhibitors such as FK-506 may have clinical potential in the treatment of refractory neonatal seizures.

\section{Materials and Methods}

Hypoxia-induced seizures. All protocols were approved by the institutional animal care and use committee. Rat pups were maintained in a $12 \mathrm{~h}$ light/dark cycle facility. To induce hypoxic seizures, we followed our previously published methods (Jensen et al., 1991, 1992). Briefly, rat pups at ages $\mathrm{P} 10-\mathrm{P} 11$ were exposed to global hypoxia (reducing $\mathrm{O}_{2}$ to $4-7 \%$ by infusion of $\mathrm{N}_{2}$ gas into the chamber) for $15 \mathrm{~min}$, and the number of myoclonic jerks and tonic clonic seizures were counted during the period of hypoxia.

Hippocampal slice preparation. Rat pups were killed by decapitation $1 \mathrm{~h}$ after hypoxia treatment with all procedures in accordance with guidelines set by the institutional animal care and use committee. Brain tissues were rapidly dissected from the skull and placed in cold artificial CSF (ACSF; see below for ACSF composition) bubbled with $95 \% \mathrm{O}_{2} / 5 \% \mathrm{CO}_{2}$ at $4^{\circ} \mathrm{C}$. Hippocampal slices of $400 \mu \mathrm{m}$ thickness were prepared using a vibratome in cold ACSF according to our previously published protocol (Jensen et al., 1998; Sanchez et al., 2001).

Electrophysiology. Electrophysiological studies used whole-cell patchclamp recordings from CA1 pyramidal neurons of acutely removed hippocampal slices. Slices were incubated in a chamber with continuously oxygenated ACSF at room temperature for at least $1 \mathrm{~h}$ before electrophysiological recordings.

Whole-cell patch-clamp recordings were obtained from visually identified individual CA1 pyramidal neurons using Nikon (Tokyo, Japan) infrared/differential interference contrast optics microscopy. Patchclamp recordings were made in whole-cell mode as described previously (Dai et al., 1998, 2002; Sanchez et al., 2001), and the slices were continuously superfused with ACSF bubbled with $95 \% \mathrm{O}_{2} / 5 \% \mathrm{CO}_{2}$ at $0.5-1$ $\mathrm{ml} / \mathrm{min}$ containing the following (in $\mathrm{mM}$ ): $124 \mathrm{NaCl}, 5 \mathrm{KCl}, 1.25$ $\mathrm{NaH}_{2} \mathrm{PO}_{4}, 2 \mathrm{CaCl}_{2}, 1.3 \mathrm{MgSO}_{4}, 26 \mathrm{NaHCO}_{3}$, and 10 D-glucose, $\mathrm{pH}$ 7.3. The internal solution of the patch pipette consisted of the following (in mM): 123 Cs-gluconate, $4 \mathrm{NaCl}, 2 \mathrm{MgCl}_{2}, 10$ EGTA, 10 HEPES, $2 \mathrm{Na}$ ATP, and 0.3 GTP, pH 7.2, for spontaneous IPSC recordings. For recording-evoked IPSCs and GABA-evoked currents, Cs-gluconate was replaced by $123 \mathrm{~mm} \mathrm{CsCl}$ to achieve near equimolar $\mathrm{Cl}^{-}$in the internal and external solutions. Filled electrodes had resistances of 4-5 M $\Omega$. All experiments were made at room temperature $\left(22-24^{\circ} \mathrm{C}\right)$. Signals were digitized and recorded on a personal computer, and data were analyzed using the pClamp 8 software package (Axon Instruments, Union City, CA). After baseline spontaneous IPSC (sIPSC) recordings, specific AMPAR antagonists CNQX (20 $\mu \mathrm{M}$; Sigma, St. Louis, MO), 1-(4aminophenyl)-4-methyl-7,8-methylenedioxy-5H-2,3-benzodiazepine hydrochloride (GYKI 52466; $30 \mu \mathrm{M}$; Tocris Cookson, Ballwin, MO), and Joro spider toxin (JSTx; $1 \mu \mathrm{M}$; Calbiochem, La Jolla, CA); NMDAR antagonist D-AP-5 (50 $\mu \mathrm{M}$; Sigma); and immunosuppressant drugs FK-506 (1 $\mu \mathrm{M}$; Calbiochem) and rapamycin (500 nм; Sigma) were applied through a gravity superfusion system to the bath. For some experiments,
CaN activity was blocked by the specific inhibitor CaN autoinhibitory peptide ( $200 \mu \mathrm{M}$; Calbiochem) added in the patch electrode solution. All drug-induced alterations in synaptic currents were completely reversed by 30 min to $1 \mathrm{~h}$ washout in ACSF except with intracellular application of CaN autoinhibitory peptide. Series resistance was checked by hyperpolarizing voltage steps and was typically $5-18 \mathrm{M} \Omega$. Experiments were terminated if the series resistance increased by $>20 \%$.

To evoke IPSCs, single stimulus shocks at low frequency (one per $30 \mathrm{~s}$ ) and $100 \mu$ s duration were delivered through a bipolar tungsten electrode placed in the stratum radiatum to activate Schaffer collateralcommissural inputs. Stimulus intensity/response curves were obtained $(50-200 \mu \mathrm{A})$, and the stimulus intensity that elicited $60 \%$ of the maximum response was used for the duration of experiments to examine drug-induced effects on evoked IPSCs. The recording electrode was placed in cell layer in stratum pyramidale of area CA1 and $\sim 200 \mu \mathrm{m}$ away from the stimulating electrode. To evoke pure IPSCs, experiments were performed in the presence of glutamate receptor antagonists NBQX $(20 \mu \mathrm{M})$ and D-AP-5 (50 $\mu \mathrm{M})$ to block EPSCs. Data were collected using an Axopatch 200A amplifier (Axon Instruments) with compensation for series resistance and cell capacitance, filtered at $2 \mathrm{kHz}$, and digitized at 10 $\mathrm{kHz}$ using a Digidata 1320A. sIPSC detection was performed, and frequency and amplitude histograms were constructed using Mini-Analysis (Synaptosoft, Decatur, GA). The detection parameters used were $3 \mathrm{pA}$ threshold, $50 \mathrm{pA}$ area, and decay to 0.37 of the peak for the decay time constant, with no averaging of points for the peak calculation. The statistical significance of the difference was assessed using Student's $t$ test ( $p<0.05$ was considered significant). Intergroup comparisons were analyzed with one-way ANOVA test.

Immunoblotting. At 1 and $24 \mathrm{~h}$ after exposure to hypoxia in vivo, rats were killed by decapitation, and hippocampal brain tissue was dissected out and placed in cold ethanol. The tissue was then homogenized in a buffer containing the following: $1 \mathrm{~mm}$ EDTA, $1 \mathrm{~mm}$ EGTA, 1\% Triton $\mathrm{X}-100,2.5 \mathrm{~mm}$ sodium pyrophosphate, $1 \mathrm{~mm} \beta$-glycerolphosphate, $1 \mathrm{~mm}$ sodium orthovanadate, $1 \mu \mathrm{g} / \mathrm{ml}$ leupeptin, and $1 \mathrm{~mm}$ phenylmethylsulfonyl in Tris-buffered saline ( $20 \mathrm{~nm}$ Tris and $150 \mathrm{~mm} \mathrm{NaCl}, \mathrm{pH}$ 7.5). After centrifugation $(14,000 \times g ; 10 \mathrm{~min})$, the pellet was discarded to obtain the cytosolic portion of the cell. A Bradford protein assay (Bio-Rad, Hercules, CA) was performed to determine the protein concentration of each sample. The same lysis buffer used in homogenization was then added to bring each sample to an equal concentration.

SDS-PAGE was performed on $10 \%$ Tris- $\mathrm{HCl}$ gels (Bio-Rad). After transfer to polyvinylidene diflouride membranes, gels were stained with Coomassie Brilliant Blue R-250 stain (Bio-Rad) to check for consistent protein loading across lanes. After transfer, membranes were blocked for $1 \mathrm{~h}$ at $20^{\circ} \mathrm{C}$ with $5 \%$ nonfat dry milk in Tris-buffered saline (100 mm Tris and $154 \mathrm{~mm} \mathrm{NaCl}, \mathrm{pH} 7.5$ ) with $1 \mathrm{ml} / \mathrm{L}$ Tween 20 (TBST). Membranes were then incubated overnight at $4^{\circ} \mathrm{C}$ with monoclonal anti-CaN $(\alpha$ subunit) primary antibody (Sigma) at a concentration of 1:13,000. After this, membranes were rinsed three times for $15 \mathrm{~min}$ with TBST and then incubated for $1 \mathrm{~h}$ at $20^{\circ} \mathrm{C}$ with horseradish peroxidase-conjugated antimouse IgG secondary antibody (Jackson ImmunoResearch, West Grove, $\mathrm{PA}$ ) at a concentration of 1:3000. Blots were again rinsed three times for 15 min each (Rosenberg et al., 2003).

For phosphoamino acid analysis, $\mathrm{GABA}_{\mathrm{A}} \mathrm{R} \beta 2 / 3$ subunits were immunoprecipitated using a mouse monoclonal IgG anti-GABA ${ }_{A} \mathrm{R} \beta 2 / 3$ antibody (Upstate Biotechnology, Lake Placid, NY). Precipitated material was separated by SDS-PAGE and transferred to a nitrocellulose membrane. Western blot analysis was then performed, using the same protocol as described above, using a specific mouse monoclonal IgG $_{1}$ antiphospho-serine/threonine antibody (Upstate Biotechnology).

For testing the effect of FK-506 and NBQX on CaN protein expression $24 \mathrm{~h}$ after hypoxic seizures, the $\mathrm{P} 10$ rats were rendered hypoxic in vivo and then injected with FK-506 (10 mg/kg) or saline vehicle $30 \mathrm{~min}$ before hypoxia and $6 \mathrm{~h}$ after hypoxia or $20 \mathrm{mg} / \mathrm{kg}$ NBQX immediately and $12 \mathrm{~h}$ after hypoxia. Both treatment groups were killed at $24 \mathrm{~h}$ after hypoxia for Western blot analysis of hippocampal tissue.

Signal bands corresponding to protein and phosphoamino acid were then visualized using the SuperSignal West Femto maximum sensitivity chemiluminescence substrate (Pierce, Rockford, IL), and the relative op- 
tical signal density was measured using Kodak (Rochester, NY) 1D Image Analysis software (Christensen et al., 2000). Relative optical density measurements were then expressed as a percentage of the control mean density, and $\mathrm{CaN}$ levels of hypoxic animals were compared with those of littermate controls using Student's $t$ test.

CaN activity assay. At $1 \mathrm{~h}$ after hypoxic seizures, $\mathrm{P} 10$ rats were decapitated, and dissected hippocampi were placed immediately in icecold ACSF bubbled with $95 \% \mathrm{O}_{2} / 5 \% \mathrm{CO}_{2}$. CA1 minislices were made (12-16 per rat) and frozen on dry ice. CA1 regions were homogenized into $500 \mu \mathrm{l}$ of ice-cold homogenization buffer containing the following (in $\mathrm{mm}$ ): 5 HEPES, $\mathrm{pH}$ 7.0, 7 EGTA, 5 EDTA, 1 dithiothreitol (DTT), 0.03 phenylmethylsulfonyl fluoride, and 300 sucrose. Homogenates were then normalized for protein, separated into aliquots, and stored at $-80^{\circ} \mathrm{C}$ until use. CaN activity was then assayed using the procedure detailed by Kurz et al. (2001). All reaction tubes were prepared on ice and contained the following: $25 \mathrm{~mm}$ morpholinopropanesulfonic acid, $\mathrm{pH}$ 7.0, 1 mm DTT, 2 mu $p$-nitrophenol phosphate (pNPP), and 150 nM okadaic acid. Basal tubes contained the addition of 2 mM EGTA and 2 mм EDTA. Maximal tubes also contained $2 \mathrm{~mm} \mathrm{MnCl}_{2}$. $\mathrm{Mn}^{2+}$ activates calcineurin more strongly than $\mathrm{Ca}^{2+}$ (Pallen and Wang, 1983), and therefore, $\mathrm{Mn}^{2+}$ was used in maximal reactions to best visualize the cation-stimulated activity of the enzyme. Reactions were initiated by the addition of $100 \mu \mathrm{g} / \mathrm{ml}$ CA1 homogenate. Total final reaction volumes were $300 \mu \mathrm{l}$. Reactions were incubated at $37^{\circ} \mathrm{C}$ for $30 \mathrm{~min}$ in a shaking water bath. Tubes were then removed from the water bath and placed on ice to stop the reaction. Next, each reaction mixture was transferred to a 96-well plate in triplicate with $80 \mu \mathrm{l}$ per well plate, and $p$-nitrophenol (pNP) produced was visualized by the addition of $40 \mu \mathrm{l}$ of $3 \mathrm{~m} \mathrm{NaOH}$. Absorbance of the reaction mixture was immediately measured at 405 $\mathrm{nm}$ in a plate reader, and absorbance units were converted to micrograms per milliliter of pNP produced by comparison with a pNP concentration standard absorption curve. To measure the effects of GYKI 52466 on CaN activity in CA1 minislices from hypoxic rats, we used the CaN phosphatase assay (Biomol, Plymouth Meeting, PA) as per Shi et al. (2000).

\section{Results}

IPSC frequency and amplitude in CA1 pyramidal neurons were decreased $1 \mathrm{~h}$ after hypoxia-induced seizures

sIPSCs were recorded under whole-cell voltage clamp from visually identified CA1 pyramidal neurons in acute slices of the hippocampus removed at $1 \mathrm{~h}$ after hypoxia-induced seizures in vivo (see Materials and Methods). To isolate GABA-mediated events without pharmacological disruption of the hippocampal circuitry, cells were voltage clamped at $+10 \mathrm{mV}$, the approximate reversal potential for glutamate receptors. In CA1 pyramidal neurons, both sIPSC frequency and amplitude were significantly decreased in slices from
A Control
Hypoxia
Bicuculline

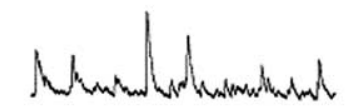

B

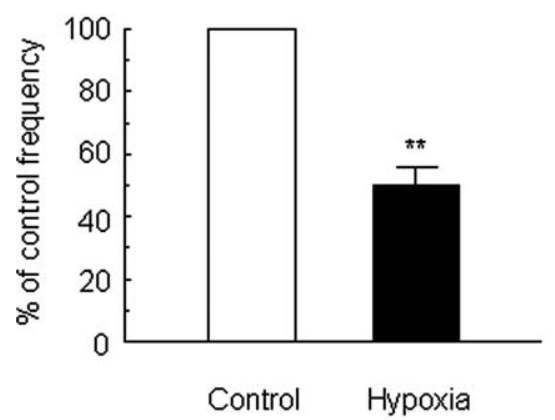

Ca

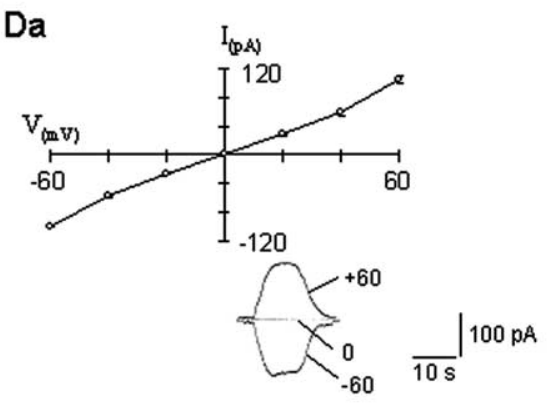

Figure 1. $G_{A B A} R$-mediated sIPSC $s$ and elPSC $s$ were significantly deceased in CA1 pyramidal neurons after hypoxia-induced seizures. $\boldsymbol{A}$, Representative traces show outward sIPSCs with cells voltage clamped at $10 \mathrm{mV}$. The sIPSC frequency and amplitudes clearly were decreased in slices removed at $1 \mathrm{~h}$ after hypoxia-induced seizures in P10 rat pups compared with slices from littermate controls. The addition of bicuculline methiodide completely abolished spontaneous events, confirming that the synaptic currents were mediated by $G_{A B A_{A} R s . ~}$, Pooled data (mean \pm SEM) showed a significant decrease in sIPSC frequency and amplitude in slices from hypoxia-treated pups $\left(0.82 \pm 0.1 \mathrm{~Hz},{ }^{* *} p<0.01 ; 12.9 \pm 1.4 \mathrm{pA} ; n=5\right.$ cells per group; $\left.{ }^{*} p<0.05\right)$ compared with controls (1.68 $\pm 0.2 \mathrm{~Hz}$ and $19.1 \pm 1.5 \mathrm{pA} ; n=5$; Student's $t$ test). (Data shown are normalized to control values.) $(\boldsymbol{a}$, Superimposed representative traces show that elPSCs induced by single stimulus shocks were markedly reduced after hypoxiainduced seizures. $\boldsymbol{C} \boldsymbol{b}$, The amplitudes of elPSCs were significantly decreased in slices from hypoxia-treated rats (13.7 $\pm 1.4 \mathrm{pA}$; $n=9$ ) compared with control rats $\left(45.1 \pm 4.7 \mathrm{pA} ; n=8 ;{ }^{* * *} p<0.0001\right)$. D, Current-voltage plots for GABA-evoked currents showed no difference in the reversal potential between the control group $(\mathbf{D a})$ and hypoxia-treated group $(\boldsymbol{D} \boldsymbol{b})$, indicating that a persistent shift in reversal potential could not have explained the difference in IPSC amplitudes between groups. Traces in the inset are current responses to $10 \mathrm{~s}$ applications of GABA $(100 \mu \mathrm{m})$ recorded under the same conditions as eIPSCs.

\section{$\mathrm{Db}$}
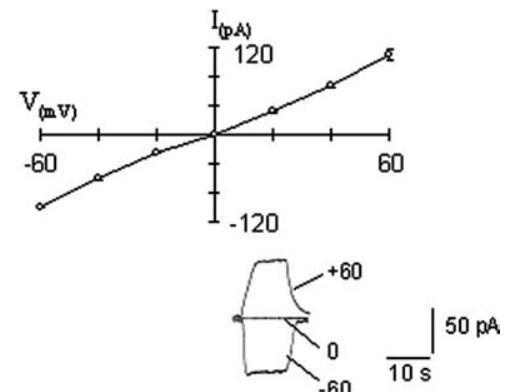

hypoxia-treated animals compared with those from littermate controls. sIPSCs were completely blocked by bath application of the $\mathrm{GABA}_{\mathrm{A}} \mathrm{R}$ antagonist bicuculline methiodide $(20 \mu \mathrm{M})$ (Fig. $\left.1 A\right)$, confirming that they were mediated by $\mathrm{GABA}_{\mathrm{A}}$ Rs. The mean sIPSC frequency in the hypoxia-treated group was decreased by $51.5 \pm$ $5.6 \%(1.68 \pm 0.2 \mathrm{~Hz}$ for control and $0.82 \pm 0.1 \mathrm{~Hz}$ for hypoxiatreated rats; $n=5 ; p<0.01)$, and the mean amplitude was decreased by $32.7 \pm 7.1 \%(19.1 \pm 1.5 \mathrm{pA}$ for control and $12.9 \pm 1.4 \mathrm{pA}$ for 
hypoxia-treated rats; $p<0.05 ; n=5$ cells per group) (Fig. $1 A, B$ ). Notably, the decay time constants of sIPSCs in the hypoxia-treated group were markedly increased compared with controls from $38.12 \pm 1.67 \mathrm{~ms}(n=36$; control group) to $75.81 \pm 3.37 \mathrm{~ms}(n=38$ cells; hypoxia-treated group; $p<0.0001$ ). The $10-90 \%$ rise time was not significantly altered after hypoxia-induced seizures ( $7.64 \pm 0.49$ ms for control rats, $n=36$ cells per group; $8.72 \pm 0.35 \mathrm{~ms}$ for hypoxic rats, $n=38$ cells).

We also examined evoked IPSCs (eIPSCs) in slices from hypoxia-treated and littermate control rats in response to single electrical stimuli applied to the Schaffer collateral axons in area CA1. Stimuli were applied at a very low frequency (one per $30 \mathrm{~s}$ ) in the presence of the glutamate receptor antagonists NBQX (20 $\mu \mathrm{M})$ and D-AP-5 $(50 \mu \mathrm{M})$ to block EPSCs while holding the cells at $-60 \mathrm{mV}$. As illustrated in Figure $1 B$, eIPSC amplitudes were significantly decreased by $69.6 \pm 3.2 \%$ after hypoxia-induced seizures with $45.1 \pm 4.7 \mathrm{pA}(n=8)$ for controls and $13.7 \pm 1.4 \mathrm{pA}$ $(n=9 ; p<0.0001)$ for hypoxia-treated group (Fig. 1C). Additionally, current-voltage relationships generated for responses to direct GABA application $(100 \mu \mathrm{M})$ under the same condition (except with $1 \mu \mathrm{M}$ TTX added) indicated no differences between groups in the $\mathrm{GABA}_{\mathrm{A}} \mathrm{R}$ reversal potential (Fig. $1 D$ ), thus ruling out a potential contribution of an altered $\mathrm{Cl}^{-}$gradient to the decreased IPSC amplitudes in the hypoxia-treated group. Together, these data indicate that the hypoxia-induced seizures cause an early decrease in basal GABAergic synaptic inhibition of CA1 pyramidal neurons.

\section{Decrease in GABAergic inhibition is dependent on CaN activity}

$\mathrm{CaN}$ (calcineurin, phosphatase 2B) is a $\mathrm{Ca}^{2+}$-calmodulindependent serine/threonine protein phosphatase that is distributed widely throughout the brain and can regulate the activity of several ligand-gated ion channels, including $\mathrm{GABA}_{\mathrm{A}}$ receptors (for review, see Yakel, 1997). CaN has also been reported to mediate activity-dependent decreases in GABAergic inhibition to CA1 pyramidal neurons (Yakel, 1997; Lu et al., 2000). We therefore asked whether $\mathrm{CaN}$ may contribute to the decrease in basal synaptic GABAergic inhibition observed in CA1 pyramidal neurons after acute hypoxia-induced seizures. In slices removed from P10 rats immediately after hypoxia-induced seizures in vivo, bath application of the CaN inhibitor FK-506 ( $1 \mu \mathrm{M})$ significantly increased the mean sIPSC frequency to $216.2 \pm 22.7 \%$ of posthypoxia baseline (from $0.82 \pm 0.1 \mathrm{~Hz}$ for untreated to $1.77 \pm 0.19$ $\mathrm{Hz}$ with FK-506 treatment; $p<0.01)$ and increased the mean sIPSC amplitude to $134.3 \pm 4.5 \%$ of posthypoxia baseline (from $12.9 \pm 1.4 \mathrm{pA}$ for untreated to $17.3 \pm 0.8 \mathrm{pA}$ for FK-506-treated slices; $p<0.05$; before drug, $n=5$; FK-506, $n=4)$ (Fig. $2 A, B)$. In contrast, FK-506 had no effect on sIPSC amplitudes and frequency in neurons from the control group. The increases in sIPSC amplitudes and frequency in the FK-506-treated group were fully reversible after $>30$ min of washout of FK-506 (Fig. $2 C, D$ ). Interestingly, the prolonged decay time constants of sIPSCs in the hypoxia-treated group were significantly decreased after FK-506 application from 78.1 \pm 16.6 to $61.8 \pm 15.8 \mathrm{~ms}(n=$ 6; $p<0.02$ ), consistent with a previous report of sIPSC shortening after inhibition of CaN (Jones and Westbrook, 1997).

To determine whether the effects of FK-506 on GABAergic IPSCs could have been caused by actions other than CaN inhibition, we examined the effects of the immunosuppressant rapamycin. Rapamycin is a derivative of FK-506 that also binds to the immunophilin FKBP12, but, unlike FK-506, the FKBP12rapamcyin complex does not inhibit CaN activity (Victor et al.,
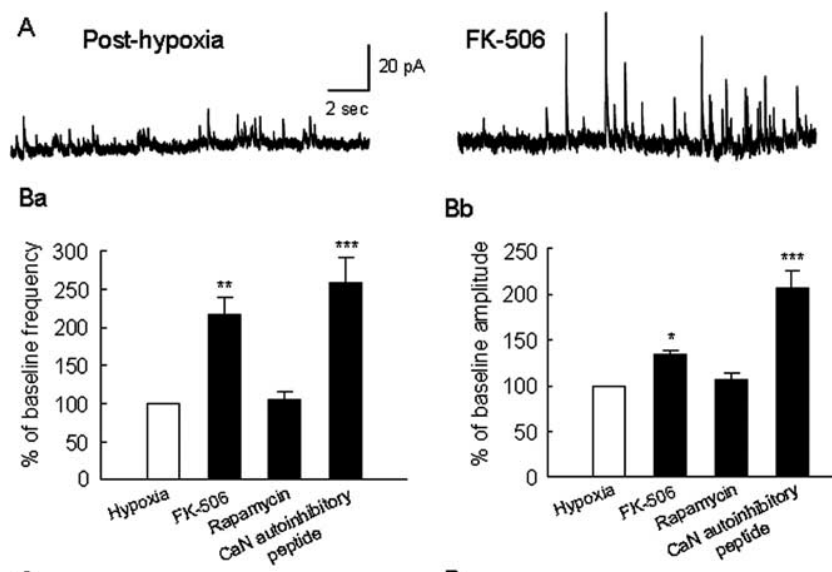

$\mathrm{Bb}$
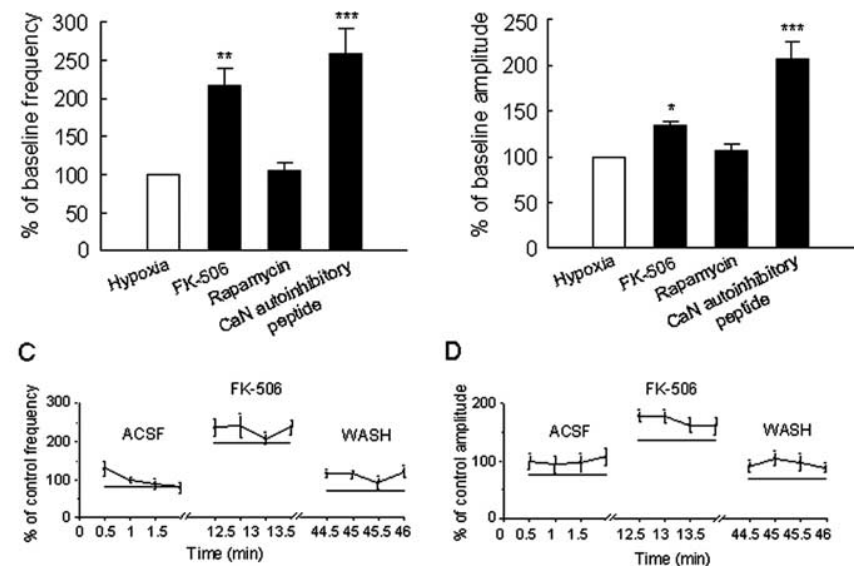

。

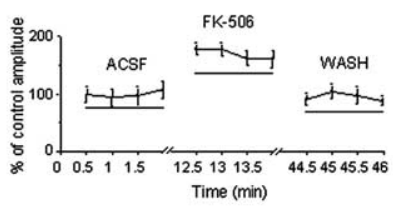

E

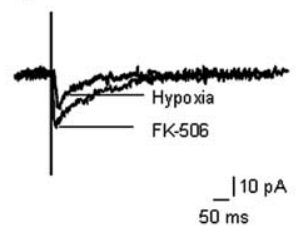

F

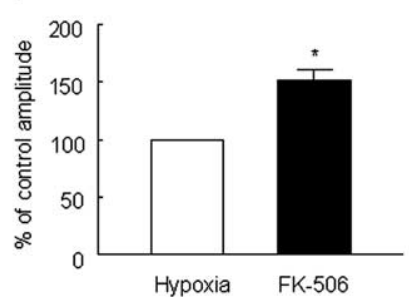

Figure 2. $\quad \boldsymbol{A}$, Inhibition of CaN activity reversed the decreases in SIPSC amplitude and frequency in hippocampal CA1 pyramidal neurons after hypoxia-induced seizures. $\boldsymbol{B}$, sIPSC frequency $(0.82 \pm 0.1 \mathrm{~Hz})$ and amplitudes $(12.9 \pm 1.4 \mathrm{pA})$ in cells from the hypoxia-treated group were significantly increased by application of FK-506, 1.77 $\pm 0.19 \mathrm{~Hz}\left({ }^{* *} p<0.01\right)$ and $17.3 \pm$ $0.8 \mathrm{pA}$ ( ${ }^{*} p<0.05$; before drug, $n=5 ;$ FK-506, $\left.n=4\right)$, respectively. sIPSC frequency $(0.85 \pm$ $0.06 \mathrm{~Hz}$ ) and amplitudes $(7.7 \pm 0.6 \mathrm{pA})$ also were significantly increased after CaN autoinhibitory peptide application to $2.2 \pm 0.28 \mathrm{~Hz}$ and $15.8 \pm 1.5 \mathrm{pA}$, respectively $\left(n=6\right.$; ${ }^{* * *} p<$ 0.001). In contrast, no significant changes were observed in sIPSC frequency and amplitudes after rapamycin application (prerapamycin values were $0.88 \pm 0.08 \mathrm{~Hz}$ and $9.5 \pm 0.7 \mathrm{pA}, n=$ 6 , and postrapamycin values were $0.93 \pm 0.08 \mathrm{~Hz}$ and $10.2 \pm 0.6 \mathrm{pA}, n=6$, for frequency and amplitude, respectively). $\boldsymbol{C}, \boldsymbol{D}$, The effects of bath application of FK-506 recovered with washout. $\boldsymbol{E}$, Superimposed representative traces show that the decreased eIPSC amplitude after hypoxia-induced seizures also was significantly reversed by bath application of FK-506. $\boldsymbol{F}$, Pooled data showed that FK-506 treatment significantly reversed the eIPSC amplitude ( $n=6$; $\left.{ }^{*} p<0.05\right)$. The mean amplitudes of elPSCs were $13.7 \pm 1.4 \mathrm{pA}(n=9)$ before FK-506 and $20.8 \pm 1.3 \mathrm{pA}(n=6)$ after FK-506.

1995; Phillis et al., 2002). Application of rapamycin (500 nM) had no significant effect on sIPSC frequency and amplitudes in CA1 neurons in slices removed immediately after hypoxia-induced seizures. After rapamycin, the mean sIPSC frequency and amplitude were not significantly changed [106 $\pm 9 \%(0.88 \pm 0.08 \mathrm{~Hz}$ for untreated; $0.93 \pm 0.08 \mathrm{~Hz}$ for rapamycin-treated slices) and $107.1 \pm 6.4 \%(9.5 \pm 0.7 \mathrm{pA}$ for untreated; $10.2 \pm 0.6 \mathrm{pA}$ for rapamycin-treated slices; $n=6 ; p>0.05$ )] (Fig. $2 A, B$ ). Thus, the FK-506 effects are likely to be attributable to its ability to inhibit CaN activity.

To further determine whether the effects of FK-506 were specifically attributable to $\mathrm{CaN}$ inactivation, we examined the effects of intracellular application of the specific $\mathrm{CaN}$ autoinhibitory peptide (Shi et al., 2000). Similar to FK-506, the CaN autoinhibitory peptide $(200 \mu \mathrm{M})$ resulted in a significant increase in sIPSC amplitudes in neurons in slices from hypoxia-treated rats by 
$206.1 \pm 19.9 \%$ (from $7.7 \pm 0.6$ to $15.8 \pm 1.5 \mathrm{pA} ; n=6 ; p<0.001)$ compared with neurons recorded from the same slices without the CaN autoinhibitory peptide. Surprisingly, intracellular application of the CaN autoinhibitory peptide to the postsynaptic cells also increased sIPSC frequency by $258.6 \pm 32.9 \%$ (from $0.85 \pm$ 0.06 in the untreated hypoxic group to $2.2 \pm 0.28 \mathrm{~Hz}$ in the $\mathrm{CaN}$ autoinhibitory peptide group; $n=6$; $p<0.001$ ) (Fig. $2 A, B$ ). Although the mechanism by which this occurred remains speculative, increased sIPSC frequency after a purely postsynaptic decrease in phosphatase activity is consistent with a previous report of increased sIPSC frequency in CA1 pyramidal neurons after purely postsynaptic application of free $\mathrm{Ca}^{2+}$-calmodulin to increase $\mathrm{Ca}^{2+}$-calmodulin-dependent kinase activity (Wei et al., 2004) (see Discussion).

We further examined the effects of FK-506 on evoked IPSCs. Consistent with its effect on sIPSC amplitudes, FK-506 increased eIPSC amplitudes in neurons from the hypoxia-treated group (Fig. $2 E, F)$ by $51.5 \pm 9.5 \%(13.7 \pm 1.4 \mathrm{pA}, n=9$, for the untreated group; $20.8 \pm 1.3 \mathrm{pA}, n=6$, for FK-506-treated rats; $p<$ 0.05). In contrast, eIPSC amplitudes in neurons from control slices were not affected by FK-506 (data not shown).

\section{CaN activity is elevated in hippocampal slices after hypoxia-induced seizures}

The effects of CaN inhibition on IPSCs in neurons from the hypoxia-treated group suggested that $\mathrm{CaN}$ activity may be persistently elevated in slices obtained from these animals. To determine whether $\mathrm{CaN}$ is elevated after hypoxia-induced seizures, we used a biochemical assay for CaN activity in slices from control and hypoxia-treated animals. In the $\mathrm{CaN}$ activity assay used here, $\mathrm{CaN}$ dephosphorylates the low-molecular weight compound pNPP with high affinity, producing pNP (Pallen and Wang, 1983). This dephosphorylation is easily measured by spectrophotometry, providing an accurate method for assaying CaN activity. Both basal and $\mathrm{Mn}^{2+}$ maximally stimulated CaN activity were measured using this assay procedure in area CA1 at $1 \mathrm{~h}$ after hypoxic seizures. Slices from the hypoxia-treated group exhibited a significant increase in $\mathrm{CaN}$ phosphatase activity in both basal and maximal conditions. The average basal activity in control slices was $19.07 \pm 1.778(n=6)$ compared with $32.99 \pm 0.627$ in the hypoxia-treated group $(n=8 ; p<0.001)$, an increase of $72.98 \pm 3.289 \%$. The average maximal activity in control slices was $25.85 \pm 5.837(n=6)$ compared with $46.46 \pm 6.627$ in the hypoxia-treated group $(n=8 ; p<0.001)$, an increase of $67.19 \pm$ $12.83 \%$ (Fig. 3A). These increases in hippocampal CaN activity after hypoxia-induced seizures were coincident with the observed decreases in $\mathrm{GABA}_{\mathrm{A}} \mathrm{R}$-mediated inhibition in CA1 pyramidal neurons, suggesting that the inhibition of $\mathrm{CaN}$ and consequent potentiation of GABAergic inhibition served specifically to reverse effects of the hypoxia-induced seizures.

To determine whether the observed increase in CaN activity is associated with elevated $\mathrm{CaN}$ protein expression, we measured total hippocampal $\mathrm{CaN}$ protein levels at $1 \mathrm{~h}$ after hypoxiainduced seizures by Western blot analysis. Immunoblots using antibodies to the $\mathrm{CaN}-\mathrm{A} \alpha$ subunit were performed on hippocampal whole-cell protein from $\mathrm{P} 10$ rat pups killed at 1, 6, and $24 \mathrm{~h}$ after hypoxia-induced seizures at P10. As shown in Figure $3 B$, CaN-A $\alpha$ expression was unchanged at $1 \mathrm{~h}$ after hypoxia compared with control levels ( $n=5$ animals per group). These data indicate that the acute increase in CaN activity measured $1 \mathrm{~h}$ after hypoxia-induced seizures is not likely a result of a rapid increase in $\mathrm{CaN}$ expression but rather from an increase $\mathrm{CaN}$ activation state or kinetics, similar to that reported in adult status epilepti-
A

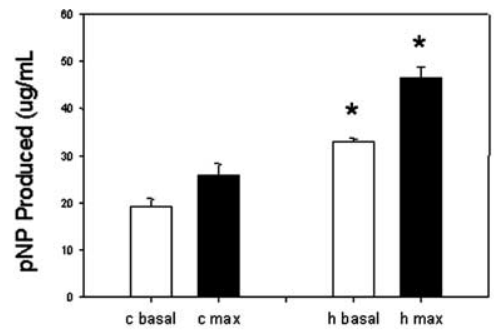

$\mathrm{Ba}$

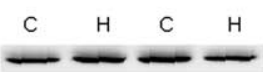

$\mathrm{Bb}$
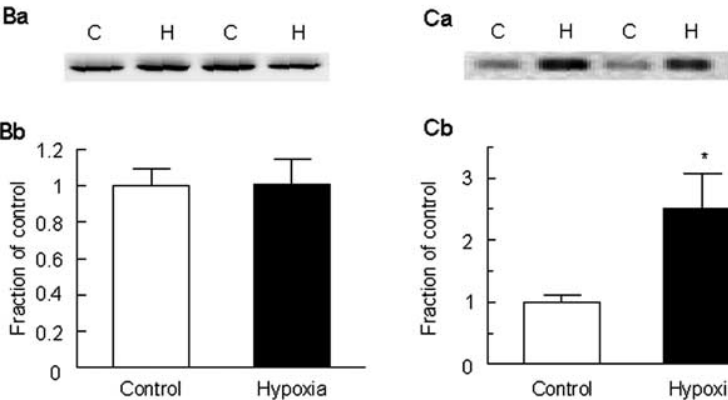

$\mathrm{Cb}$

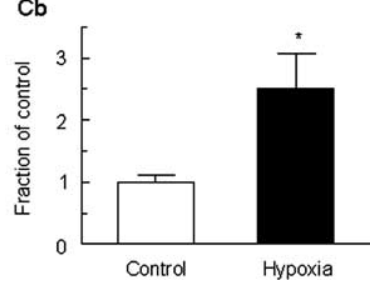

Figure 3. Increased CaN phosphatase activity after hypoxia-induced seizures. $\boldsymbol{A}$, Hypoxiainduced seizures resulted in a significant increase in control basal CaN (c basal) and maximal control CaN (c max) activity. Basal and maximal CaN activity levels were assayed in homogenates from area CA1 of hippocampus at $1 \mathrm{~h}$ after hypoxia. CaN activity was significantly increased in hypoxia samples (black, h basal, h max) compared with control samples (white, c basal, c max) at both basal levels ( ${ }^{*} p<0.001 ; n=6$; Student's $t$ test) and $\mathrm{Mn}^{2+}$ stimulated maximal levels ( ${ }^{*} p<0.001 ; n=6$; Student's $t$ test). Western blot analyses of CaN protein expression were performed in hippocampal homogenates reacted with monoclonal CaN-A $\alpha$ antibody at $1 \mathrm{~h}(\mathbf{B a})$ and $24 \mathrm{~h}(\mathbf{C a})$ after hypoxia-induced seizures $(\mathrm{H})$ and compared with controls (C). B b , Histogram from pooled data shows that at $1 \mathrm{~h}$ after hypoxia, hippocampal CaN protein expression was not significantly different from that of controls $(n=5 ; p>0.05)$, whereas hippocampal homogenates removed at $24 \mathrm{~h}(\boldsymbol{C b})$ after hypoxia-induced seizures showed a significant increase in CaN protein compared with controls $\left(n=6 ;{ }^{*} p<0.05\right)$.

cus models (Kurz et al., 2001). At 6 h after hypoxia, we observed a modest but nonsignificant increase (10\%) in CaN-A $\alpha$ expression ( $n=5$ per group) (data not shown). However, at $24 \mathrm{~h}$ after hypoxia-induced seizures, $\mathrm{CaN}-\mathrm{A} \alpha$ expression was significantly increased ( $2.5 \pm 0.6$-fold; $n=6$ per group) (Fig. 3C) compared with littermate controls $(1.0 \pm 0.1 ; n=6 ; p<0.05)$. Thus, there appears to be a gradual increase in CaN expression over a $24 \mathrm{~h}$ period after hypoxia-induced seizures that may contribute to a long-term decrease in basal GABAergic inhibition of CA1 principal neurons.

\section{Serine/threonine residues of $\mathrm{GABA}_{\mathrm{A}} \mathrm{R} \boldsymbol{\beta} 2 / 3$ subunits are} dephosphorylated after hypoxia-induced seizures

Phosphorylation sites have been identified on $\mathrm{GABA}_{\mathrm{A}} \mathrm{R} \beta$ subunits, and receptor phosphorylation state modifies $\mathrm{GABA}_{\mathrm{A}} \mathrm{R}$ function (Moss et al., 1992; Krishek et al., 1994; McDonald et al., 1998). Protein kinase A-mediated phosphorylation of adjacent Ser-408 and Ser-409 sites on $\beta 3$ subunits in $\alpha 1 \beta 3$-containing receptors increases responsivity to GABA application (McDonald et al., 1998), and, thus, dephosphorylation of $\mathrm{GABA}_{\mathrm{A}} \mathrm{R}$ $\beta 3$ subunits could be expected to decrease $G_{A B A} R$-mediated responses to synaptic GABA release. We measured the phosphorylation state of $\mathrm{GABA}_{\mathrm{A}} \mathrm{R} \beta 2 / 3$ subunits after hypoxia-induced seizures using anti-phospho serine/threonine antibodies against immunoprecipitated $\mathrm{GABA}_{\mathrm{A}} \mathrm{R} \beta 2 / 3$ subunit protein. At $1 \mathrm{~h}$ after hypoxia-induced seizures, there was a significant decrease in the level of phosphorylation of serine/threonine residues in $\mathrm{GABA}_{\mathrm{A}} \mathrm{R}$ $\beta 2 / 3$ subunits by $35.4 \pm 5.1 \%$ of the control with no alteration in 
total $\beta 2 / 3$ subunit protein $(n=6 ; p<0.001)$ (supplemental Fig. 1 , available at www.jneurosci.org as supplemental material). These findings suggest that $\mathrm{GABA}_{\mathrm{A}} \mathrm{Rs}$ are likely targets of $\mathrm{CaN}$ mediated dephosphorylation and support the hypothesis that hypoxia-induced decreases in IPSC amplitudes are attributable to, in part, $\mathrm{GABA}_{\mathrm{A}} \mathrm{R}$ downmodulation consequent to $\mathrm{GABA}_{\mathrm{A}} \mathrm{R}$ dephosphorylation.

\section{Inhibition of AMPARs, but not NMDARs, mimics the effects of CaN inhibition}

Our data thus far demonstrate the following: (1) hypoxiainduced seizures result in acute decreases in basal synaptic inhibition of hippocampal CA1 pyramidal neurons, (2) CaN inhibition partially reverses the effects of hypoxia-induced seizures by increasing basal synaptic inhibition, and (3) seizures induce CaN activity and $\mathrm{GABA}_{\mathrm{A}} \mathrm{R}$ dephosphorylation in the hippocampus. $\mathrm{CaN}$ is a $\mathrm{Ca}^{2+}$-calmodulin-dependent phosphatase, and therefore can potentially be activated by numerous sources of activitydependent $\mathrm{Ca}^{2+}$ entry into neurons. In the P10 rat, in which susceptibility to the epileptogenic effects of hypoxia is highest (Jensen et al., 1991; Jensen, 1997), hippocampal and cortical pyramidal neurons express $\mathrm{Ca}^{2+}$-permeable AMPARs because of a maturation-dependent lower expression of the GluR2 subunit in the first 2 weeks of life (Sanchez et al., 2001; Kumar et al., 2002). Because this route of $\mathrm{Ca}^{2+}$ entry exists only in the very immature brain, we investigated whether seizure-induced activation of $\mathrm{Ca}^{2+}$-permeable AMPARs played a pivotal role in this CaNmediated signaling pathway.

After hypoxia-induced seizures in vivo, incubation of hippocampal slices with the specific AMPAR antagonist GYKI 52466 $(30 \mu \mathrm{M})$ for $1 \mathrm{~h}$ prevented the increase in CaN activity after hypoxia-induced seizures $(n=5 ; p>0.05)$ (Fig. $4 A$ ), suggesting that basal AMPAR activation is required for the seizure-induced increases in CaN activity. Additionally, application of the same concentration of GYKI 52466 to slices from the hypoxia-treated group significantly increased the sIPSC frequency by $86.2 \pm$ $19.4 \%$ from $0.76 \pm 0.03$ to $1.42 \pm 0.15 \mathrm{~Hz}(p<0.001)$ and the mean sIPSC amplitude by $35 \pm 9.6 \%$ from $7.5 \pm 0.7$ to $10.1 \pm 0.7$ pA (before drug, $n=6$; after GYKI 52466, $n=5$; $p<0.05$ ) (Fig. $4 B, C)$. In contrast, GYKI 52466 had no significant effect on sIPSC frequency or amplitude in neurons in control slices (data not shown). These data indicate that AMPAR blockade can reverse the seizure-induced activation of $\mathrm{CaN}$ and downregulation of basal GABAergic transmission to CA1 pyramidal neurons.

We further investigated whether the divalent-permeable AMPARs specifically mediate the increased CaN activity after hypoxia-induced seizures. Bath application of the specific $\mathrm{Ca}^{2+}$ permeable AMPAR antagonist JSTx $(1 \mu \mathrm{M})$ (Metzger et al., 2000) in slices obtained from hypoxia-treated animals significantly increased the mean sIPSC frequency by $79.4 \pm 23.9 \%$ from $0.80 \pm$ 0.07 to $1.44 \pm 0.19 \mathrm{~Hz}(n=6 ; p<0.01)$ and increased the mean sIPSC amplitude by $55.8 \pm 14.5 \%$ from $7.1 \pm 0.7$ to $11.1 \pm 1.0 \mathrm{pA}$ $(n=6 ; p<0.01)$ compared with controls, similar to the effects of GYKI 52466 (Fig. 4B, C). These data indicated that specific inhibition of $\mathrm{Ca}^{2+}$-permeable AMPARs could mimic the effects of $\mathrm{CaN}$ inhibition on GABAergic transmission and support the hypothesis that AMPAR-mediated $\mathrm{Ca}^{2+}$ entry into CA1 pyramidal cells can activate $\mathrm{CaN}$ to downregulate GABAergic inhibition after hypoxia-induced seizures.

NMDARs are another source of $\mathrm{Ca}^{2+}$-dependent $\mathrm{CaN}$ activation. We therefore examined the effects of NMDAR inhibition on sIPSCs. In slices obtained from hypoxia-treated animals, bath application of the specific NMDAR antagonist D-AP-5 (50 $\mu \mathrm{M})$

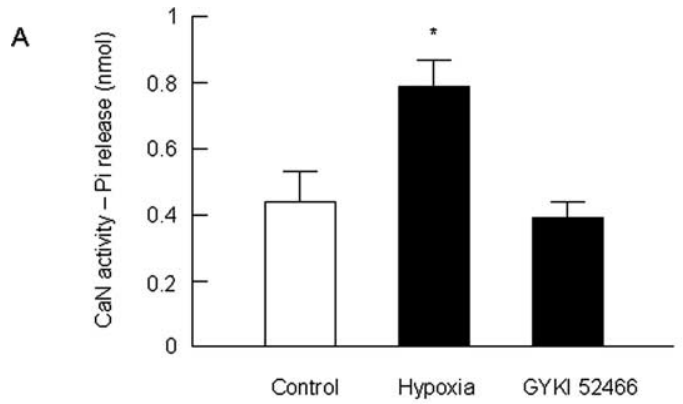

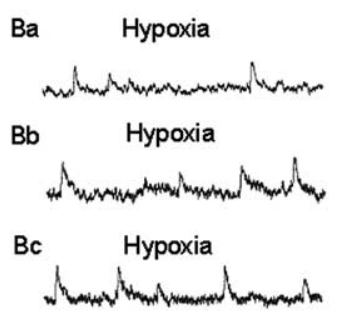

$\mathrm{Ca}$

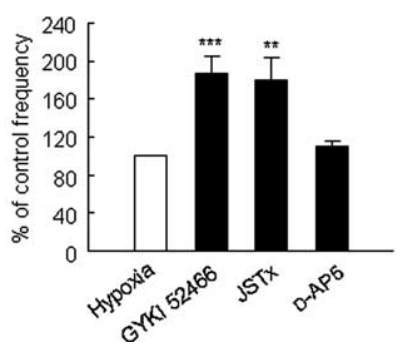

GYKI 52466

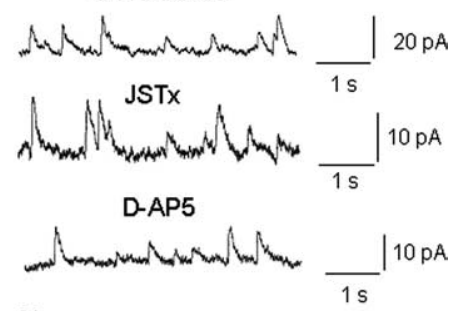

$\mathrm{Cb}$

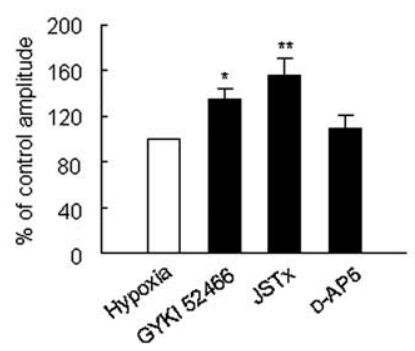

Figure 4. A, GYKI 52466 prevented the hypoxia-induced increase in CaN activity. CaN activity was significantly increased after hypoxia-induced seizures $\left(n=14\right.$; $\left.{ }^{*} p<0.05\right)$, whereas preincubation of hippocampal homogenates with GYKI 52466 (30 $\mu \mathrm{M})$ after hypoxia in vivo prevented this increase. GYKI 52466 caused no significant difference in CaN activity from the control samples $(n=5)$. $\boldsymbol{B}, \boldsymbol{C}$, Blockade of $\mathrm{Ca}^{2+}$-permeable AMPARs reversed sIPSC downregulation, whereas blockade of NMDARs did not affect sIPSCs after hypoxia-induced seizures. Application of GYKI 52466 increased sIPSC frequency and amplitude from $0.76 \pm 0.03 \mathrm{~Hz}$ and $7.5 \pm 0.7 \mathrm{pA}$ (hypoxia group) to $1.42 \pm 0.15 \mathrm{~Hz}(n=5 ; p<0.001)$ and $10.1 \pm 0.7 \mathrm{pA}$ (before drug, $n=6$; after GYKI 52466, $n=5 ; p<0.05)$, respectively, whereas JSTx increased the frequency from $0.80 \pm 0.07 \mathrm{~Hz}$ to $1.44 \pm 0.19 \mathrm{~Hz}(n=6 ; p<0.01)$ and amplitude from $7.1 \pm 0.7$ to $11.1 \pm$ $1.0 \mathrm{pA}(n=6 ; p<0.01)$. D-AP-5 did not significantly affect the decreased sIPSC frequency [frequencies were $0.85 \pm 0.05 \mathrm{~Hz}$ before drug and $0.94 \pm 0.05 \mathrm{~Hz}$ after drug $(n=5)$; amplitudes were $9.3 \pm 0.8 \mathrm{pA}$ before drug and $10.1 \pm 1.1 \mathrm{pA}$ after $\operatorname{drug}(n=5 ; p>0.05)]$.

had no significant effect in CA1 pyramidal neurons on either sIPSC frequency (increase of $10.1 \pm 6 \%$ from $0.85 \pm 0.05$ to $0.94 \pm 0.05 \mathrm{~Hz} ; n=5$ ) or amplitudes (increase of $9.0 \pm 12.1 \%$ from $9.3 \pm 0.8$ to $10.1 \pm 1.1 \mathrm{pA} ; n=5$ ) (Fig. $4 B, C)$. These results indicate that NMDARs do not play a major role in the specific seizure-induced changes in GABAergic inhibition observed in this model and, in addition, support the hypothesis that this form of epileptogenic plasticity at this maturational stage is primarily dependent on $\mathrm{Ca}^{2+}$ entry through AMPARs.

\section{Spontaneous EPSCs are not downregulated after hypoxia-induced seizures}

To determine whether hypoxia-induced seizures may result generally in suppression of synaptic transmission, we next investigated whether AMPAR-mediated spontaneous EPSCs (sEPSCs) were altered after hypoxia-induced seizures. In contrast to the effects on sIPSCs, the frequency of sEPSCs in CA1 pyramidal neurons in slices from the hypoxia-treated group was signifi- 
A

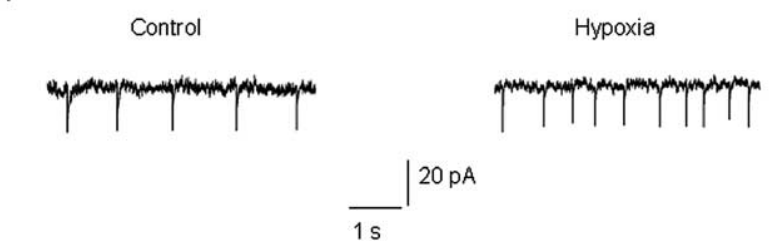

B
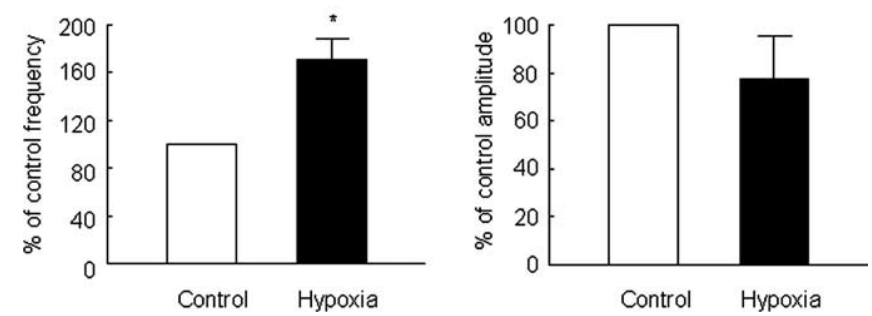

Figure 5. Regulation of $s$ EPSCs in CA1 pyramidal neurons after hypoxia-induced seizures at P10. $A$, Representative traces show that the sEPSC frequency (but not amplitude) was significantly increased after hypoxia-induced seizures. $\boldsymbol{B}$, Summary of the regulation of $s E P S C S$ after hypoxic seizures from the pooled data shows that the $S E P S C$ frequency was significantly increased from $1.13 \pm 0.17 \mathrm{~Hz}(n=4)$ to $1.94 \pm 0.19 \mathrm{~Hz}\left(n=7 ;{ }^{*} p<0.05\right)$, whereas the amplitude was not significantly changed, with values of $24.3 \pm 9.2 \mathrm{pA}(n=4)$ for controls and $18.8 \pm 4.4 \mathrm{pA}(n=7)$ for the hypoxia-treated group.

cantly increased by $71.5 \pm 17.2 \%$ from $1.13 \pm 0.17$ to $1.94 \pm 0.19$ $\mathrm{Hz}(p<0.05)$ compared with controls, whereas sEPSC amplitudes were not significantly altered (decrease of $22.7 \pm 18.0 \%$ from $24.3 \pm 9.2, n=4$, to $18.8 \pm 4.4 \mathrm{pA}, n=7$ ) (Fig. $5 A, B)$. Hence, hypoxia-induced seizures do not appear to result in a nonspecific downregulation of synaptic transmission. The increased sEPSC frequency further suggests that an upregulation of AMPAR-mediated synaptic activity after hypoxia-induced seizures may contribute to the activation of intracellular $\mathrm{CaN}$ and the potentially consequent downregulation of $\mathrm{GABA}_{\mathrm{A}} \mathrm{R}$ mediated IPSCs.

FK-506 systemic treatment suppresses hypoxia-induced seizures and prevents increases in $\mathrm{CaN}$ in vivo

Our in vitro results suggest that perinatal hypoxia-induced seizures lead to a persistent decrease in basal GABAergic synaptic inhibition of CA1 pyramidal neurons that is mediated by $\mathrm{CaN}$ activity. Because the induction of CaN activity may occur on a relatively rapid time scale, we determined whether this mechanism could contribute to the acute seizures that result from hypoxia in vivo. To test this, we first assessed the effects of in vivo pretreatment with FK-506 on the frequency of seizures induced by hypoxia in P10 rat pups. Animals were injected with either saline or FK-506 (10 mg/kg, i.p.) $30 \mathrm{~min}$ before exposure to global hypoxia. FK-506 significantly decreased the number of seizures induced by hypoxia compared with saline-treated hypoxic rats, with the mean number of seizures at $0.6 \pm 1.4$ in pups treated with FK-506 compared with $8.4 \pm 7.5$ in saline-injected controls $(p<0.001)$ (Fig. 6A).

The protective effect of FK-506 could be attributable to its ability to block seizure occurrence or to block an effect secondary to seizure occurrence. To evaluate the second possibility, we examined whether FK-506 treatment after hypoxia affected the increased seizure susceptibility, which we have previously observed as a consequence of hypoxic seizures at P10 (Jensen et al., 1995; Koh and Jensen, 2001). Rat pups were exposed to global hypoxia at P10, and immediately after hypoxia, animals received injec-
A
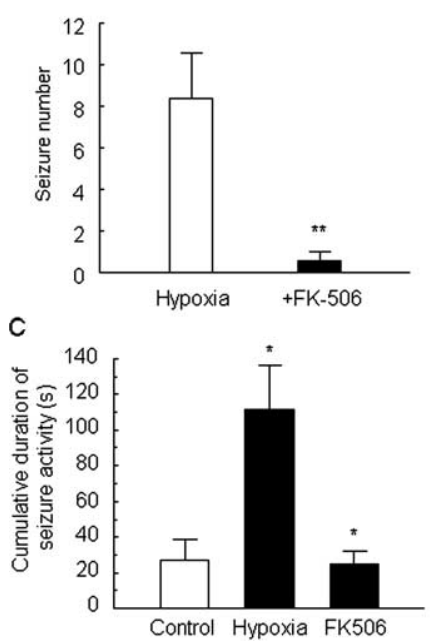

B

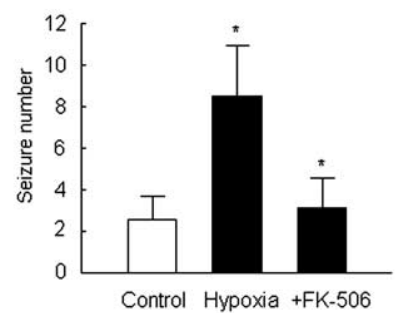

D

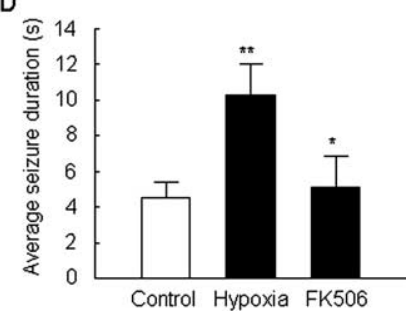

Figure 6. Effect of FK-506 treatment on seizure incidence during perinatal hypoxia. Rat pups received doses of FK-506 (10 mg/kg, i.p.). A, Pretreatment of FK-50630 min before exposure to global hypoxia; FK-506 significantly decreased the seizure incidence $(n=12)$ induced by hypoxia compared with control vehicle injection (hypoxia alone) $\left(n=11\right.$; $\left.{ }^{* *} p<0.001\right)$. $\boldsymbol{B}$, Immediately after hypoxia, animals received injections of FK-506 or saline vehicle. Control animals also received injections of saline vehicle at this time. Injections were repeated at 8 and $16 \mathrm{~h}$ after hypoxia. The total number of seizures was significantly increased in the hypoxic group $(n=10)$ compared with control animals $(n=11)$, and FK-506 significantly blocked this effect $(n=10$; $\left.{ }^{*} p<0.05\right)$. C, FK-506 treatment $(n=8)$ blocked the significant increases in cumulative seizure duration $(n=7)$ compared with controls $\left(n=6 ;{ }^{*} p<0.005\right)$. $\boldsymbol{D}$, In addition, the average length of a seizure was also significantly increased in the hypoxic group $(n=7)$ for animals that seized during hypoxia at P11 compared with controls $(n=6)$ and FK-506-treated animals ( $n=$ $\left.8 ;{ }^{* *} p<0.05\right)$.

tions of FK-506 (10 mg/kg, i.p.) or saline vehicle with repeated injection at 8 and $16 \mathrm{~h}$. Additional control animals (no hypoxia) also received injections of saline vehicle intraperitoneally. At P11, $24 \mathrm{~h}$ after hypoxia and $8 \mathrm{~h}$ after the final injection, all animals received a second exposure to hypoxia. The total number of seizures with a second hypoxia exposure was significantly increased in the previous hypoxic group $(8.5 \pm 2.4)$ compared with control animals $(2.5 \pm 1.2)$, and FK-506 significantly blocked this effect $(3.1 \pm 1.5 ; p<0.05)$ (Fig. $6 B)$. In addition, the cumulative duration of seizure activity was significantly increased in rats with previous hypoxia (111.7 $\pm 24.6 \mathrm{~s})$ compared with controls $(27.2 \pm 11.3 \mathrm{~s})$, and this increase was blocked by FK-506 (24.6 \pm $7.9 \mathrm{~s} ; p<0.005$ ) (Fig. 6C). Finally, the average seizure duration was significantly increased in the hypoxic group $(10.3 \pm 1.7 \mathrm{~s})$ compared with controls $(4.5 \pm 0.9 \mathrm{~s})$ and FK-506-treated animals $(5.1 \pm 1.1 \mathrm{~s} ; p<0.05)$ (Fig. $6 D)$. The observed anticonvulsant effect of FK-506 combined with our in vitro data is consistent with the hypothesis that seizures can activate $\mathrm{CaN}$ and that this may be an early critical step in the generation of hypoxia-induced hyperexcitability and seizures.

NBQX and FK-506 systemic treatment blocks seizure-induced increases in $\mathrm{CaN}$ expression

$\mathrm{CaN}$ expression is increased at $24 \mathrm{~h}$ after hypoxia and thus may contribute to longer-lasting network excitability. We have shown previously that NBQX treatment after seizures blocks long-term epileptogenesis in this model (Koh et al., 2004). We therefore hypothesized that the increase of $\mathrm{CaN}$ expression may be regulated by early AMPAR activation. NBQX treatment after hypoxia (20 mg/kg, i.p., immediately after and at $12 \mathrm{~h}$ after hypoxia) prevented the increase in CaN expression $(94.9 \pm 8.1 \%$ of con- 


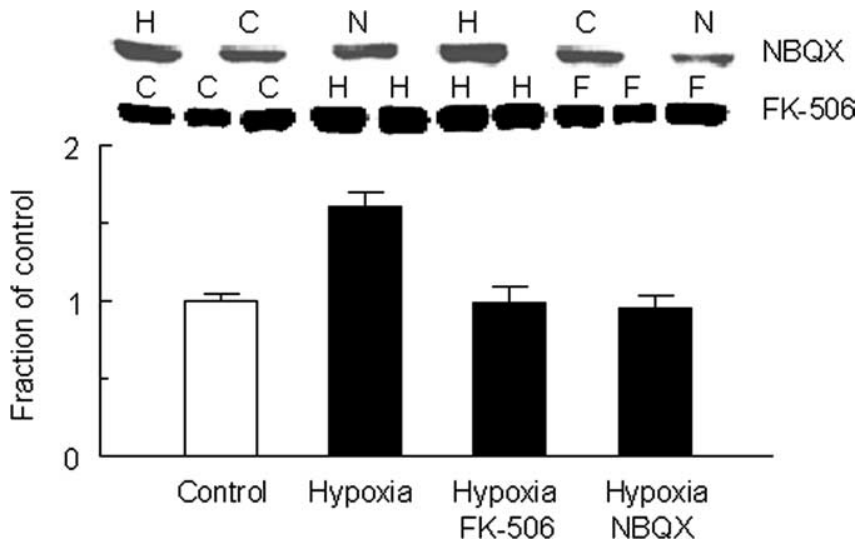

Figure 7. CaN expression was significantly increased $24 \mathrm{~h}$ for the hypoxia group $(\mathrm{H})$ $(156.2 \pm 12.8 \%$ of control; $n=8 ; p<0.05)$. FK-506 treatment (F) $(10 \mathrm{mg} / \mathrm{kg}) 30 \mathrm{~min}$ before hypoxia and $6 \mathrm{~h}$ after hypoxia reversed CaN expression to control (C) levels (98.6 $\pm 9.7 \%$ of control; $n=5 ; p<0.05)$. NBQX treatment (N) $(20 \mathrm{mg} / \mathrm{kg})$ immediately after and at $12 \mathrm{~h}$ after hypoxia also suppressed the increase in CaN expression ( $94.9 \pm 8.1 \%$ of the control; $n=4 ; p<$ 0.05) compared with the saline-treated hypoxic pups.

trol; $n=4)$ compared with vehicle-treated hypoxic rats (156.2 \pm $12.8 \%$ of control; $n=8 ; p<0.05$ ) (Fig. 7). These results suggest that continued AMPAR activation after seizures may contribute to the delayed increase in CaN expression.

\section{Discussion}

Hypoxia-induced seizures cause early increases in hippocampal excitability that require AMPAR and CaN activation

Our previous work demonstrated enhanced long-term potentiation and "in vitro kindling" in area CA1 of hippocampal slices removed from P10 rat pups at $10 \mathrm{~min}$ after hypoxia-induced seizures, indicating an early immediate increase in hippocampal network excitability (Jensen et al., 1998). The present study reveals a novel signaling pathway mediated by $\mathrm{CaN}$ that is likely to be involved in this early seizure-induced hippocampal hyperexcitability and suggests that $\mathrm{Ca}^{2+}$-permeable AMPARs activated by hypoxia-induced seizures are sufficient for $\mathrm{CaN}$ activation. Hypoxia-induced seizures decreased basal $\mathrm{GABA}_{\mathrm{A}} \mathrm{R}$-mediated synaptic inhibition of CA1 pyramidal neurons, and this effect was partially reversed by $\mathrm{CaN}$ inhibition, raising the possibility that increased $\mathrm{CaN}$ activity contributed to the decreased inhibition. This was further supported by the observation that CaN activity was persistently increased under conditions in which GABAergic inhibition was decreased. Additionally, both the increase in CaN activity and the decrease in GABAergic inhibition were reversed or prevented by the blockade of AMPARs by GYKI 52466 and the specific blockade of $\mathrm{Ca}^{2+}$-permeable AMPARs by JSTx, suggesting that increased $\mathrm{CaN}$ activation was triggered by glutamateevoked entry of $\mathrm{Ca}^{2+}$ through AMPARs. Finally, a role for a $\mathrm{CaN}$-dependent pathway in the generation of hypoxia-induced seizures and epileptogenesis in vivo was supported by our observation that the CaN inhibitor FK-506 both inhibited hypoxiainduced seizures and significantly inhibited the increased expression of $\mathrm{CaN} 24 \mathrm{~h}$ after hypoxia treatment. Together, these findings suggest that hypoxia-induced seizures in the immature brain result in AMPAR-mediated $\mathrm{Ca}^{2+}$ entry into CA1 pyramidal neurons, which persistently elevates $\mathrm{CaN}$ activity and results in a persistent downregulation of synaptic GABAergic inhibition of these neurons. This represents a novel and possibly agespecific signaling pathway that regulates hippocampal excitabil- ity and may contribute to the increased seizure susceptibility of the immature brain (Sanchez and Jensen, 2001).

\section{Endogenous $\mathrm{CaN}$ activation regulates $\mathrm{GABA}_{\mathrm{A}} \mathrm{R}$ synaptic inhibition}

CaN activation has been implicated in activity-induced downregulation of synaptic GABAergic inhibition and decreased $\mathrm{GABA}_{\mathrm{A}} \mathrm{R}$-mediated responses to GABA (Chen and Wong, 1995; Huang and Dillon, 1998; Lu et al., 2000). Although downmodulation of GABAergic inhibition may be mediated by multiple mechanisms in our model, our results suggest that one factor may be the dephosphorylation of serine/threonine phosphorylation sites on $\mathrm{GABA}_{\mathrm{A}} \beta 2 / 3$ subunits. The serine residues within the $\beta 3$ subunit are key residues for modulating $G_{A B A} R$ function (Brandon et al., 1999, 2000), and dephosphorylation by CaN can decrease $\mathrm{GABA}_{\mathrm{A}} \mathrm{R}$-mediated responses to GABA (Chen and Wong, 1995), increase the rate of GABA unbinding (Jones and Westbrook, 1997), and decrease cell surface $\mathrm{GABA}_{\mathrm{A}}$ receptor stability (Connolly et al., 1999). The $\mathrm{GABA}_{\mathrm{A}} \beta 2 / 3$ protein also has been shown to undergo endocytosis after ictal activity in cultured hippocampal neurons, contributing to subsequent hyperexcitability (Blair et al., 1999). In this study, we showed that hypoxiainduced seizures resulted in decreased $\mathrm{GABA}_{\mathrm{A}} \mathrm{R}$ phosphorylation concomitant with a decrease in IPSC amplitudes, and furthermore, the decrease in IPSC amplitudes could be partially reversed by $\mathrm{CaN}$ inhibition. These results strongly suggest $\mathrm{CaN}$-mediated dephosphorylation of $\mathrm{GABA}_{\mathrm{A}} \mathrm{Rs}$ as one mechanism of downmodulation of GABAergic inhibition after hypoxia-induced seizures.

Notably, the frequency of sIPSCs also was decreased after hypoxia-induced seizures, and this was partially reversed by $\mathrm{CaN}$ inhibition. Surprisingly, this effect was observed with CaN inhibition only in the recorded cell, a scenario in which drug-induced modulation of presynaptic interneuron firing or transmitter release would be unexpected. Nonetheless, intracellular application of free $\mathrm{Ca}^{2+}$-calmodulin to CA1 pyramidal neurons to promote $\mathrm{Ca}^{2+}$-calmodulin-dependent kinase activity was observed previously to increase sIPSC frequency in these cells (Wei et al., 2004). Although the mechanism by which this occurred has yet to be addressed, our observation of increased sIPSC frequency after inhibition of $\mathrm{CaN}$ phosphatase activity is consistent with this finding.

\section{Calcineurin activation after hypoxia-induced seizures}

Our data indicated that the hypoxia-induced seizures caused a persistent increase in basal and maximal CaN activity without a change in $\mathrm{CaN}$ protein. These data suggested that $\mathrm{CaN}$ kinetics were altered by hypoxia. Notably, an early increase in basal and maximal CaN activity also has been reported in the adult brain after experimental status epilepticus (Kurz et al., 2001). $\mathrm{Ca}^{2+}$ influx through GluRs regulates $\mathrm{Ca}^{2+}$-dependent intracellular enzymes such as CaN (Snyder et al., 1998b; Morioka et al., 1999; Vignes, 2001; Shibasaki et al., 2002) and calcium/calmodulindependent protein kinase II (CaMKII) (Kochan et al., 2000), and $\mathrm{CaN}$ can be activated by increased intracellular $\mathrm{Ca}^{2+}$ specifically through AMPAR activation (Nishi et al., 2002). CaN is inhibited by phosphorylation by protein kinase $\mathrm{C}$ and CaMKII (Hashimoto et al., 1990; Kurz et al., 2001), and CaMKII has been reported to be downregulated in adult status epilepticus models (Churn et al., 2000; Kochan et al., 2000). We recently reported a similar downregulation of CaMKII expression after hypoxiainduced seizures (Lippman et al., 2001), raising this as another potential mechanism for persistent removal of $\mathrm{CaN}$ inhibition. 
CaN activity also can be increased by $\mathrm{Ca}^{2+}$-stimulated protease calpain I (Kurz et al., 2001). Calpain is activated by injury such as trauma (Buki et al., 1999) and hypoxia/ischemia (White et al., 2000) and, therefore, might also be a factor in this model.

\section{$\mathrm{Ca}^{2+}$-permeable AMPARs regulate GABAR activity through activation of $\mathrm{CaN}$}

Previous studies have shown that GluR activation is involved in the regulation of GABAergic synaptic inhibition (Chen and Wong, 1995; Vizi and Kiss, 1998; Vignes, 2001). We observed that the AMPAR antagonist GYKI 52466 blocked CaN activation, and both GYKI 52466 and the $\mathrm{Ca}^{2+}$-permeable AMPAR antagonist JSTx significantly reversed the decrease in sIPSC amplitudes and frequency in CA1 pyramidal neurons after hypoxia-induced seizures, mimicking the effects of $\mathrm{CaN}$ inhibition alone. The most likely explanation for this was that $\mathrm{Ca}^{2+}$-permeable AMPARmediated activation of $\mathrm{CaN}$ resulted in $\mathrm{CaN}$-mediated downmodulation of GABAergic inhibition. It is worth mentioning that in our voltage-clamp experiments, sIPSCs were recorded at the predicted AMPAR reversal potential $(+10 \mathrm{mV})$, and $\mathrm{Ca}^{2+}$ permeable AMPARs exhibit a voltage-dependent channel block by intracellular polyamines (Koh et al., 1995), resulting in smaller macroscopic currents. Thus, one might expect that $\mathrm{Ca}^{2+}$ would be unable to enter recorded cells under this condition. However, because we did not include a polyamine in our recording pipette, a strong channel block by intracellular polyamines would not be expected, because native polyamines likely would be diluted by diffusion into the pipette solution. Additionally, our measured sIPSC rise times were considerably longer than those reported previously. Although this may have indicated that our recordings were less than optimal (i.e., higher than estimated series resistance, spatially remote events), this would not have been expected to contribute to the drug effects or differences between groups, because there was no difference in rise times between groups.

Notably, inhibition of NMDARs by the specific antagonist D-AP-5 had no effect on sIPSCs in CA1 pyramidal neurons after hypoxia-induced seizures, indicating that the modulation of GABAergic inhibition was mediated specifically by AMPARs. Although NMDAR activation has been shown to modulate $\mathrm{GABA}_{\mathrm{A}}$ Rs in a CaN-dependent manner (Chen and Wong, 1995), other studies have shown no NMDAR-dependent modulation of sIPSCs in cultured hippocampal neurons (Vignes, 2001) and in cerebellar slices (Brickley et al., 2001). The coupling of ion channels to the regulation of intracellular enzymes certainly depends on many factors, such as cell type and experimental preparation. Our results indicate that seizure-induced $\mathrm{CaN}$ activation and modification of GABAergic inhibition in CA1 pyramidal neurons in the immature brain are mediated by AMPAR activation.

\section{Implications for epileptogenesis after hypoxia-induced seizures}

We showed previously that systemic treatment with the AMPAR antagonist NBQX blocks the acute and long-term epileptogenic effects of perinatal hypoxia (Jensen et al., 1995). Additionally, we demonstrated that hippocampal and cortical expression of the AMPAR subunit GluR2 is lower in the P10-P12 rat brain compared with adult and is further decreased within 72-96 h after hypoxia-induced seizures, with an associated increase in expression of divalent-permeable AMPARs by CA1 pyramidal neurons (Sanchez et al., 2001). Importantly, posttreatment with NBQX also prevents long-term changes, suggesting that seizure-induced persistent activation of an AMPAR-mediated signaling pathway contributes to epileptogenesis in this setting (Jensen et al., 1995; Koh and Jensen, 2001). Our present results raise a mechanism by which pathologically increased AMPAR-mediated $\mathrm{Ca}^{2+}$ influx may immediately promote hippocampal hyperexcitability via CaN-mediated downmodulation of GABAergic inhibition. Furthermore, the delayed increase in AMPAR-mediated $\mathrm{Ca}^{2+}$ influx may prolong this hyperexcitability during a critical window of developmental plasticity, potentially enabling the formation of inappropriate synaptic circuitry. Finally, the decrease in GABAergic inhibition throughout these acute and subacute phases would be expected to enhance AMPAR-mediated $\mathrm{Ca}^{2+}$ influx by failing to provide adequate opposing synaptic inhibition.

FK-506 preadministration to rat pups significantly decreased the number of seizures induced by hypoxia, and FK-506 posttreatment blocked subsequent increases in seizure susceptibility, supporting the hypothesis that activation of CaN contributes to hypoxia-induced seizures and hyperexcitability in vivo. Inhibition of CaN may represent a feasible target for age-specific therapy to acutely decrease hippocampal excitability and disrupt long-term epileptogenesis. Indeed, NBQX and FK-506 treatment are anticonvulsant and suppress the seizure-induced increases in $\mathrm{CaN}$ expression in this in vivo model. FK-506 is currently used clinically as an immunosuppressant, but it also is a potent CaN inhibitor (Snyder et al., 1998b). In addition, there are a number of FK-506 analogs that possess neuroprotective actions because of their ability to inhibit CaN without the immunosuppressant effects (Snyder et al., 1998a; Morioka et al., 1999). Our data indicate that FK-506 and/or its analogs may have clinical potential in the treatment of refractory perinatal seizures.

\section{References}

Bergamasco B, Penna P, Ferrero P, Gavinelli R (1984) Neonatal hypoxia and epileptic risk: a clinical prospective study. Epilepsia 25:131-146.

Bernes SM, Kaplan AM (1994) Evolution of neonatal seizures. Pediatr Clin North Am 41:1069-1104.

Blair RE, Churn SB, Sombati S, Lou JK, DeLorenzo RJ (1999) Long-lasting decrease in neuronal $\mathrm{Ca}^{2+} /$ calmodulin-dependent protein kinase II activity in a hippocampal neuronal culture model of spontaneous recurrent seizures. Brain Res 851:54-65.

Brandon NJ, Uren JM, Kittler JT, Wang H, Olsen R, Parker PJ, Moss SJ (1999) Subunit-specific association of protein kinase $C$ and the receptor for activated C kinase with GABA type A receptors. J Neurosci 19:9228-9234.

Brandon NJ, Delmas P, Kittler JT, McDonald BJ, Sieghart W, Brown DA, Smart TG, Moss SJ (2000) GABA $_{\mathrm{A}}$ receptor phosphorylation and functional modulation in cortical neurons by a protein kinase $\mathrm{C}$-dependent pathway. J Biol Chem 275:38856-38862.

Brickley SG, Farrant M, Swanson GT, Cull-Candy SG (2001) CNQX increases GABA-mediated synaptic transmission in the cerebellum by an AMPA/kainate receptor-independent mechanism. Neuropharmacology 41:730-736.

Buki A, Siman R, Trojanowski JQ, Povlishock JT (1999) The role of calpainmediated spectrin proteolysis in traumatically induced axonal injury. J Neuropathol Exp Neurol 58:365-375.

Chen QX, Wong RK (1995) Suppression of $\mathrm{GABA}_{\mathrm{A}}$ receptor responses by NMDA application in hippocampal neurones acutely isolated from the adult guinea-pig. J Physiol (Lond) 482:353-362.

Christensen KV, Dai WM, Lambert JD, Egebjerg J (2000) Larger intercellular variation in $(\mathrm{Q} / \mathrm{R})$ editing of GluR6 than GluR5 revealed by single cell RT-PCR. NeuroReport 11:3577-3582.

Churn SB, Kochan LD, DeLorenzo RJ (2000) Chronic inhibition of $\mathrm{Ca}^{2+}$ / calmodulin kinase II activity in the pilocarpine model of epilepsy. Brain Res 875:66-77.

Connolly CN, Kittler JT, Thomas P, Uren JM, Brandon NJ, Smart TG, Moss SJ (1999) Cell surface stability of gamma-aminobutyric acid type A receptors. Dependence on protein kinase C activity and subunit composition. J Biol Chem 274:36565-36572. 
Dai WM, Ebert B, Madsen U, Lambert JD (1998) Studies of the antagonist actions of (RS)-2-amino-3-[5-tert-butyl-3-(phosphonomethoxy)-4isoxazolyl] propionic acid (ATPO) on non-NMDA receptors in cultured rat neurones. Br J Pharmacol 125:1517-1528.

Dai WM, Christensen KV, Egebjerg J, Ebert B, Lambert JD (2002) Correlation of the expression of kainate receptor subtypes to responses evoked in cultured cortical and spinal cord neurones. Brain Res 926:94-107.

Durand GM, Zukin RS (1993) Developmental regulation of RNAs encoding rat brain kainate/AMPA receptors: a northern analysis study. J Neurochem 61:2239-2246.

Hashimoto Y, Perrino BA, Soderling TR (1990) Identification of an autoinhibitory domain in calcineurin. J Biol Chem 265:1924-1927.

Huang RQ, Dillon GH (1998) Maintenance of recombinant type A gammaaminobutyric acid receptor function: role of protein tyrosine phosphorylation and calcineurin. J Pharmacol Exp Ther 286:243-255.

Jensen FE (1997) Perinatal hypoxic-ischemic brain injury: maturationdependent relation to epilepsy. Mental Retard Dev Disabil Res Rev 3:85-95.

Jensen FE, Applegate CD, Holtzman D, Belin T, Burchfiel J (1991) Epileptogenic effect of hypoxia in the immature rodent brain. Ann Neurol 29:629-637.

Jensen FE, Holmes G, Lombroso CT, Blume H, Firkusny I (1992) Age dependent long term changes in seizure susceptibility and neurobehavior following hypoxia in the rat. Epilepsia 33:971-980.

Jensen FE, Alvarado S, Firkusny IR, Geary C (1995) NBQX blocks the acute and late epileptogenic effects of perinatal hypoxia. Epilepsia 36:966-972.

Jensen FE, Wang C, Stafstrom CE, Liu Z, Geary C, Stevens MC (1998) Acute and chronic increases in excitability in rat hippocampal slices after perinatal hypoxia in vivo. J Neurophysiol 79:73-81.

Jones MV, Westbrook GL (1997) Shaping of IPSCs by endogenous calcineurin activity. J Neurosci 17:7626-7633.

Kochan LD, Churn SB, Omojokun O, Rice A, DeLorenzo RJ (2000) Status epilepticus results in an $N$-methyl-D-aspartate receptor-dependent inhibition of $\mathrm{Ca}^{2+} /$ calmodulin-dependent kinase II activity in the rat. Neuroscience 95:735-743.

Koh DS, Burnashev N, Jonas P (1995) Block of native $\mathrm{Ca}^{2+}$-permeable AMPA receptors in rat brain by intracellular polyamines generates double rectification. J Physiol (Lond) 486:305-312.

Koh S, Jensen FE (2001) Topiramate blocks perinatal hypoxia-induced seizures in rat pups. Ann Neurol 50:366-372.

Koh S, Tibayan FD, Simpson J, Jensen FE (2004) NBQX or topiramate treatment following perinatal hypoxia-induced seizures prevents later increases in seizure-induced neuronal injury. Epilepsia 45:569-575.

Krishek BJ, Xie X, Blackstone C, Huganir RL, Moss SJ, Smart TG (1994) Regulation of $\mathrm{GABA}_{\mathrm{A}}$ receptor function by protein kinase $\mathrm{C}$ phosphorylation. Neuron 12:1081-1095.

Kumar SS, Bacci A, Kharazia V, Huguenard JR (2002) A developmental switch of AMPA receptor subunits in neocortical pyramidal neurons. J Neurosci 22:3005-3015.

Kurz JE, Sheets D, Parsons JT, Rana A, DeLorenzo RJ, Churn SB (2001) A significant increase in both basal and maximal calcineurin activity in the rat pilocarpine model of status epilepticus. J Neurochem 78:304-315.

Lippman JJ, Sanchez RM, Jensen FE (2001) Decreased hippocampal expression of calcium/calmodulin-dependent kinase II following perinatal hypoxia-induced seizures. Soc Neurosci Abstr 27:558.20.

Lu YM, Mansuy IM, Kandel ER, Roder J (2000) Calcineurin-mediated LTD of GABAergic inhibition underlies the increased excitability of CA1 neurons associated with LTP. Neuron 26:197-205.

McDonald BJ, Amato A, Connolly CN, Benke D, Moss SJ, Smart TG (1998) Adjacent phosphorylation sites on $\mathrm{GABA}_{\mathrm{A}}$ receptor beta subunits determine regulation by cAMP-dependent protein kinase. Nat Neurosci $1: 23-28$

Metzger F, Kulik A, Sendtner M, Ballanyi K (2000) Contribution of $\mathrm{Ca}^{2+}$ permeable AMPA/KA receptors to glutamate-induced $\mathrm{Ca}^{2+}$ rise in embryonic lumbar motoneurons in situ. J Neurophysiol 83:50-59.

Morioka M, Hamada J, Ushio Y, Miyamoto E (1999) Potential role of calcineurin for brain ischemia and traumatic injury. Prog Neurobiol 58:1-30.

Moss SJ, Smart TG, Blackstone CD, Huganir RL (1992) Functional modulation of $\mathrm{GABA}_{\mathrm{A}}$ receptors by cAMP-dependent protein phosphorylation. Science 257:661-665.

Nishi A, Bibb JA, Matsuyama S, Hamada M, Higashi H, Nairn AC, Greengard P (2002) Regulation of DARPP-32 dephosphorylation at PKA- and Cdk5-sites by NMDA and AMPA receptors: distinct roles of calcineurin and protein phosphatase-2A. J Neurochem 81:832-841.

Painter MJ, Scher MS, Stein AD, Armatti S, Wang Z, Gardiner JC, Paneth N, Minnigh B, Alvin J (1999) Phenobarbital compared with phenytoin for the treatment of neonatal seizures. N Engl J Med 341:485-489.

Pallen CJ, Wang JH (1983) Calmodulin-stimulated dephosphorylation of p-nitrophenyl phosphate and free phosphotyrosine by calcineurin. J Biol Chem 258:8550-8553.

Phillis JW, Diaz FG, O’Regan MH, Pilitsis JG (2002) Effects of immunosuppressants, calcineurin inhibition, and blockade of endoplasmic reticulum calcium channels on free fatty acid efflux from the ischemic/reperfused rat cerebral cortex. Brain Res 957:12-24.

Rosenberg PA, Dai W, Gan XD, Ali S, Fu J, Back SA, Sanchez RM, Segal MM, Follett PL, Jensen FE, Volpe JJ (2003) Mature myelin basic proteinexpressing oligodendrocytes are insensitive to kainate toxicity. J Neurosci Res 71:237-245.

Sanchez RM, Jensen FE (2001) Maturational aspects of epilepsy mechanisms and consequences for the immature brain. Epilepsia 42:577-585.

Sanchez RM, Koh S, Rio C, Wang C, Lamperti ED, Sharma D, Corfas G, Jensen FE (2001) Decreased glutamate receptor 2 expression and enhanced epileptogenesis in immature rat hippocampus after perinatal hypoxia-induced seizures. J Neurosci 21:8154-8163.

Shi J, Townsend M, Constantine-Paton M (2000) Activity-dependent induction of tonic calcineurin activity mediates a rapid developmental downregulation of NMDA receptor currents. Neuron 28:103-114.

Shibasaki F, Hallin U, Uchino H (2002) Calcineurin as a multifunctional regulator. J Biochem (Tokyo) 131:1-15.

Snyder SH, Lai MM, Burnett PE (1998a) Immunophilins in the nervous system. Neuron 21:283-294.

Snyder SH, Sabatini DM, Lai MM, Steiner JP, Hamilton GS, Suzdak PD (1998b) Neural actions of immunophilin ligands. Trends Pharmacol Sci 19:21-26.

Victor RG, Thomas GD, Marban E, O’Rourke B (1995) Presynaptic modulation of cortical synaptic activity by calcineurin. Proc Natl Acad Sci USA 92:6269-6273.

Vignes M (2001) Regulation of spontaneous inhibitory synaptic transmission by endogenous glutamate via non-NMDA receptors in cultured rat hippocampal neurons. Neuropharmacology 40:737-748.

Vizi ES, Kiss JP (1998) Neurochemistry and pharmacology of the major hippocampal transmitter systems: synaptic and nonsynaptic interactions. Hippocampus 8:566-607.

Volpe JJ (2001) Perinatal brain injury: from pathogenesis to neuroprotection. Mental Retard Dev Disabil Res Rev 7:56-64.

Wei J, Zhang M, Zhu Y, Wang JH (2004) $\mathrm{Ca}^{2+}$-calmodulin signalling pathway up-regulates GABA synaptic transmission through cytoskeletonmediated mechanisms. Neuroscience 127:637-647.

White BC, Sullivan JM, DeGracia DJ, O’Neil BJ, Neumar RW, Grossman LI, Rafols JA, Krause GS (2000) Brain ischemia and reperfusion: molecular mechanisms of neuronal injury. J Neurol Sci 179:1-33.

Yakel JL (1997) Calcineurin regulation of synaptic function: from ion channels to transmitter release and gene transcription. Trends Pharmacol Sci $18: 124-134$. 